\title{
ASPECTOS DA ATIVIDADE DE "NOTIFICAÇÃO DE BARBEIROS " PELA POPULAÇÃO NO CONTROLE DE PANSTRONGYLUS MEGISTUS EM 12 MUNICÍPIOS DA REGIÃO NOROESTE DO ESTADO DE SÃO PAULO, BRASIL, 1974 A 1983*
}

\author{
Virgília Luna Castor de Lima** \\ Mariko Kato Yaguchi** \\ Zulimar Catarina P. V. Telles Alves**
}

\begin{abstract}
LIMA, V. L. C. de et al. Aspectos da atividade de "notificação de barbeiros" pela população no controle de Panstrongylus megistus em 12 municípios da região noroeste do Estado de São Paulo, Brasil, 1974 a 1983. Rev. Saúde públ., S. Paulo, 24: 497-505, 1990.

RESUMO: É mostrada a importância atual da atividade de "notificação de barbeiros" pela população, na vigilância epidemiológica da doença de Chagas no Estado de São Paulo. São estudadas as variaçōes ocorridas no número de notificaçōes encaminhadas pela população no período de 1974 a 1983, relativa a uma área da Região Nordeste do referido Estado, com infestação por Panstrongylus megistus. Observou-se que a população responde aos estímulos à sua participação. Verificoú-se aumento do número de notificações a partir do mês de outubro, mantendo-se similar nos meses de novembro e dezembro. Não foi encontrada relaçăo entre os índices de infestação e o de notificaçăo.
\end{abstract}

DESCRITORES: Tripanossomose Sul-Americana, prevenção. Panstrongylus, controle de insetos, normas. Participaçăo comunitária.

Na vigilância epidemiologica da doença de Chagas no Estado de São Paulo, a colaboração da população no controle da infestação por triatomíneos vetores da doença assume progressivamente, maior importância. Isto se dá porque tendo sido erradicado o Triatoma infestans, o número de domićlios infestados reduziu-se significativamente e a infestação passou a se dar por espécies como o Triatoma sordida e Panstrongylus megistus, com características predominantemente silvestres, as quais invadem episodicamente os domicilios, a partir de resíduos das matas próximas (Litvoc?, 1985, Silva ${ }^{11}, 1981$ ). Diante deste quadro, o trabatho tradicional das equipes do Programa de Controle da Superintendência de Controle de Endemias (SUCEN), que consta de pesquisa casa a casa, a intervalos de tempo predefinidos, vem tornando-se cada vez menos eficiente (em 1987 na região de Campinas, Estado de São Paulo, de 25.722 casas pesquisadas apenas 91 apresentaram infestação, o que representa $0,4 \%$ ). Quando comparada com a atividade de "atendimento à notificação de barbeiro", onde entra a colaboração do morador que, ao encontrar inseto que julga ser "barbeiro", o encaminha à rede de serviços de saúde, desencadeando a pesquisa da casa e vizinhança, esta baixa eficiência torna-se mais evidente. (Em 1987, nessa mesma região, de 197 casas examinadas no atendimento à notificação, 26 apresenta- ram infestação - 13,2\%). Desta forma, a tendência do serviço de controle é priorizar cada vez mais esta última atividade. Dada a importância da atividade de "notificação de barbeiro" pela população, no atual quadro epidemiológico do Estado de São Paulo, resolveu-se estudar as variaçōes no número de notificações, no período de 1974 a 1983, em uma área composta por 12 municípios, onde existe infestação por Panstrongylus megistus, e relacionar estas variações com as características biológicas da espécie, com o número de casas infestadas na pesquisa casa a casa e com os trabalhos educativos de estímulo à notificação de barbeiros realizado pelas equipes de campo da SUCEN.Pretende-se, com o presente estudo, fornecer subsídios para futuras modificações a serem implantadas no Programa de Controle da Doença de Chagas.

\section{MATERIAL E MÉTODO}

Foi escolhida para o estudo uma área situada na encosta ocidental da Serra da Mantiqueira, composta por doze municípios do Estado de São Paulo: Águas da Prata, Caconde, Divinolândia, Espírito Santo do Pinhal, Itobi, Mococa, Santo Antonio do Jardim, São João da Boa Vista, São José do Rio Pardo, São Sebastião da Grama, Tapiratiba e Vargem Grande do Sul (Fig. 1).

* Apresentado no XXI Congresso da Sociedade Brasileira de Medicina Tropical, São Paulo, SP, 1985.

* Superintendência de Controle de Endemias (SUCEN) - Serviço Regional 5 - Rua São Carlos, 546 - Parque Itália - 13035 - Campinas, SP - Brasil. 
A opção por esta área deu-se porque nela a infestação por Panstrongylus megistus é maior que no restante do Estado. A área situa-se, com relação ao comportamento desta espécie vetora, em "hipotética zona limítrofe" entre dois tipos de comportamento das populaçōes de Panstrongylus megistus. Ao norte desta área corresponderia a região das populações domiciliadas e ao sul a região das populações silvestres (Forattini e col. ${ }^{3}, 1977$ ).

Alguns municípios da citada área já foram alvo de vários estudos por Forattini e col. 2, 3,4,5,6 e Rocha e Silva e col. 8,9, onde foram abordados aspectos do comportamento do Panstrongylus megistus.

Escolheu-se o período de 1974 a 1983 pelo fato de que, durante o mesmo, todos os doze municípios foram submetidos à atividade de pesquisa casa a casa, em praticamente todos os anos.

O levantamento do número de notificações de "barbeiros", foi realizado por meio de dois impressos, um para os anos de 1974 a 1980 (SUSAM 018) e outro (SUCEN - SR 5 ) para os anos de 1981 a 1983.

Os dados foram contabilizados por município, por mês e por ano. Calcularam-se médias mensais do número de notificaçōes para o período de 1974 a
1983, para cada município e para a área como um todo, com a finalidade de se observar as variaçōes na quantidade mensal de notificações ao longo do ano. Verificou-se o número de notificações de "barbeiros", por ano e por município, para se observar as variações deste número ao longo do período estudado.

Averiguou-se uma possível relação entre o índice de infestação e a quantidade de notificações, tendo sido levantados os valores anuais dos índices de infestação para cada município, calculados com os dados obtidos pela pesquisa casa a casa, da seguinte forma: $n .^{2}$ de casas infestadas por ocasião da pesquisa casa a casa / n..$^{2}$ de casas pesquisadas $\times 100$, por município e por ano.

Para se observar se os municípios que mais notificaram foram também os que apresentaram maior infestação, resolveu-se ordená-los de acordo com o índice de infestação e os valores da notificação. Foram calculados, então, a média do índice de infestação por município, utilizando os índices anuais do período estudado e os respectivos desvios padrão e coeficientes de variação (coeficiente de variação $C . V .=$ Desvio Padrão/Média). Em viturde de se ter constatado uma alta dispersão dos dados de cada município em relação à média, o que

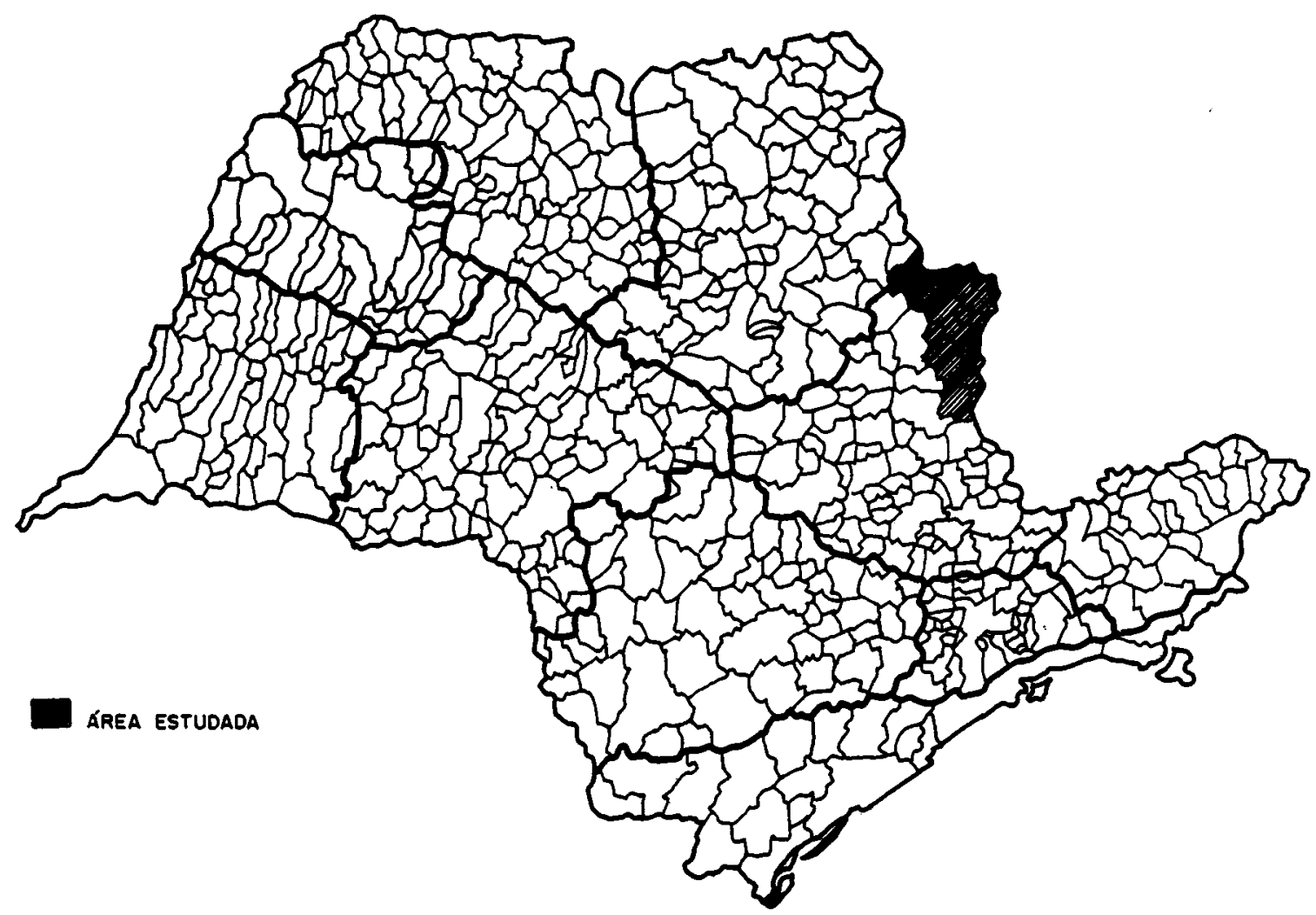

Fig. 1 - Mapa do Estado de São Paulo, assinalada a área estudada. 
poderia levar a erro na hora de ordená-los de acordo com a intensidade da infestação, resolveuse estabelecer critério para classificá-los utilizando "postos", tendo como posto de um valor, em um conjunto de valores, um número que indica sua posição no conjunto ordenado (crescente ou decrescente). Havendo valores iguais, considera-se um posto médio, de modo a não afetar os postos seguintes. No presente caso, os postos foram alocados em ordem decrescente para média e crescente para o coeficiente de variação. Isto porque se desejava classificar os municípios de maior média de índice de infestação e com menor dispersão nos primeiros lugares. Os postos da média e do coeficiente de variação foram somados e a classificação final teve como primeiro colocado - município cuja soma é a menor, e como segundo colocado o município com a segunda menor soma e, assim, sucessivamente.

Para ordenar os municípios de acordo com os valores da notificação surgiu a necessidade de se levar em consideraçăo o número de casas da zona rural de cada município. Como já mencionado, havia sido levantado o número absoluto de notificações por município, por mês e por ano. Desta forma, um município poderia apresentar um maior número de notificaçōes em relação aos outros, o que, no entanto, podia ser decorrente da existência de um maior número de casas na sua zona rural. Para levar em consideração o tamanho da zona rural dos diversos municípios, estabeleceu-se uma medida que foi denominada de "índice de notificação de barbeiro". Este índice é dado pelo valor: número de notificaçōes de barbeiro / número de casas pesquisadas $\mathrm{x}$ 100, por município e por ano. Foi utilizado o número de casas pesquisadas na atividade de pesquisa casa a casa, no denominador, por existir já, esse dado, nos impressos disponíveis na SUCEN, para o período em estudo. Este número exclui as casas fechadas e as recusas dos moradores por ocasião da visita da equipe de campo. Seria mais adequado utilizar o número de casas existentes, no entanto esse dado só aparece nos boletins a partir de 1981. Outra fonte que poderia ser utilizada para obter este dado, seria a Fundação IBGE. No entanto, de acordo com Buralli 1 , 1985, observa-se uma discrepância entre os dados da SUCEN e os do IBGE, para os números de casas da zona rural, sendo os valores desse último inferiores em relação aos da primeira. Nos anos de 1981, 1982 e 1983 a diferença entre os valores de casas pesquisadas e existentes girou em torno de $10 \%$.

Após o cálculo dos índices de notificação por ano, do período, calculou-se a média desses índices para cada município. Tendo-se observado evidente dispersão dos dados de cada município em relação à sua média, resolveu-se utilizar, para ordenar os municípios de acordo com a notificação, o mesmo artifício usado para ordená-los com o índice de infestação, alocando postos em ordem crescente para a média e decrescente para o coeficiente de varia- ção. O município considerado mais notificante foi aquele com a menor soma de postos.

Com relação ao método utilizado pelas equipes de campo, no trabalho educativo de estímulo às notificações, constava o de transmissão de informaçōes a respeito do inseto vetor e da conduta a ser seguida, no caso do achado do mesmo, na residência. Os funcionários, ao visitarem as casas na atividade de pesquisa casa a casa, mostravam ao morador um exemplar de Panstrongylus megistus, explicavam seus hábitos e sua relação com a doença de Chagas, solicitando que levassem ao Centro de Saúde do seu município todo inseto que pudesse ser "barbeiro".

\section{RESULTADOS}

Observando-se a Fig. 2, que mostra as variaçōes das médias do número de notificações ao longo do ano, nota-se uma elevação do número de notificações, representado - por tais médias, a partir do mês de outubro. Esta verificação está de acordo com os estudos de Forattini e col. ${ }^{5}$ 1979, que concluem que a dispersão ativa da espécie $P$. megistus - "ocorre principalmente a partir de outubro, prolongando-se até novembro". A invasão dos domicílios por essa espécie, durante este período, foi observada pelas equipes de campo da SUCEN e relatada também por Sherlock e Piesman 10, 1984, em trabalho realizado no Estado da Bahia.

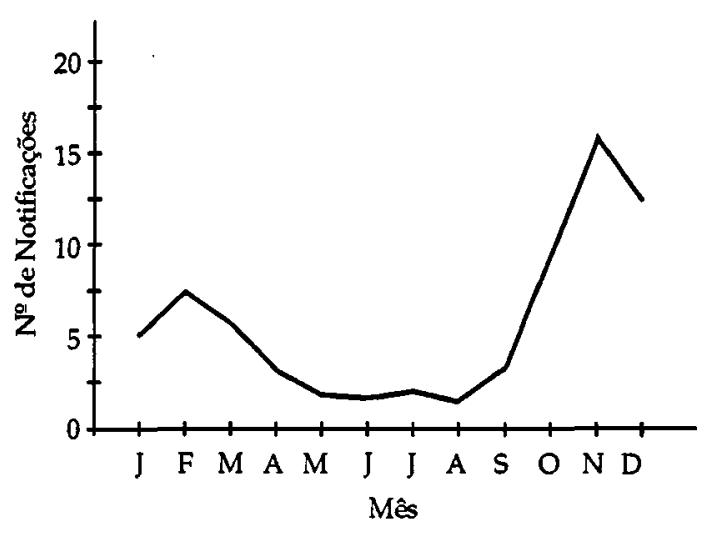

Fig. 2 - Média dos números de notificações de barbeiros por mês. Encosta pcidental da Mantiqueira Palista, 1974 a 1983.

Fonte: SUCEN = SR.5 - Campinas, SP

Observando a Tabela 1 constata-se aumento no número de notificações a partir do ano de 1982, a partir do qual as equipes de campo foram orientadas a dedicar maior tempo de suas visitas ao trabalho educativo junto aos moradores. Além disso, os atendimentos às notificações passaram a ser priorizados em relação às demais atividades do serviço de controle, de maneira que houvesse um curto intervalo 
TABELA 1

Número de "notificaçzes de barbeiros" por ano e por município da encosta ocidental da Mantiqueira Paulista, 1974 a 1983.

\begin{tabular}{|c|c|c|c|c|c|c|c|c|c|c|c|c|}
\hline Munidipio & 74 & 75 & 76 & 77 & 78 & 79 & 80 & 81 & 82 & 83 & 84 & Total \\
\hline Águas da Prata & 1 & 1 & - & 1 & 4 & 2 & 一 & 3 & 2 & 3 & 2 & 19 \\
\hline Caconde & 7 & 8 & 1 & 4 & 9 & 8 & 11 & 6 & 76 & 35 & 41 & 206 \\
\hline Divinolândia & 8 & - & 一 & - & 3 & 1 & - & 3 & 11 & 2 & 15 & 43 \\
\hline Esp. St' Pinhal & 3 & - & 4 & 2 & 3 & 3 & 3 & 3 & 18 & 10 & 19 & 68 \\
\hline Itobi & 2 & 1 & - & - & 2 & - & 1 & 4 & 6 & 6 & 5 & 27 \\
\hline Moooca & 3 & - & - & 3 & 2 & 5 & 2 & 1 & 19 & - & 7 & 42 \\
\hline St $^{8}$ Ant $^{\circ}$ Jardim & 3 & 一 & - & 一 & 一 & 3 & 2 & - & 3 & 2 & 11 & 24 \\
\hline S. J. Boa Vista & 34 & 13 & 7 & 26 & 27 & 28 & 9 & 13 & 61 & 44 & 76 & 338 \\
\hline S. J. Rio Pardo & 25 & 14 & 3 & 4 & 2 & 11 & 5 & 2 & 26 & 12 & 12 & 116 \\
\hline S. Sebast. Grama & 1 & - & 1 & 3 & 3 & - & 4 & 3 & 23 & 19 & 12 & 69 \\
\hline Tapiratiba & - & 一 & - & 2 & 1 & - & 2 & - & 6 & 1 & 10 & 22 \\
\hline Vargem Grande do Sul & 3 & - & - & 1 & - & 1 & 2 & 一 & 9 & 8 & 11 & 35 \\
\hline Total & 90 & 37 & 16 & 46 & 56 & 62 & 41 & 38 & 260 & 142 & 221 & 1.009 \\
\hline
\end{tabular}

Fonte: SR 5 - SUCEN

TABELA 2

Média (x), desvio padrão ( $\tau$ ) e coeficiente de variação (C.V.) dos índices de infestação domiciliar e peridomiciliar nos municípios da encosta ocidental da Mantiqueira Paulista, 1974 a 1983

\begin{tabular}{|c|c|c|c|c|c|c|}
\hline \multirow[b]{2}{*}{ Municípios } & \multicolumn{3}{|c|}{ Domicnlio } & \multicolumn{3}{|c|}{ Peridomicilio } \\
\hline & $x$ & $\tau$ & C.V.* & $x$ & $\tau$ & C.V.* \\
\hline Águas da Prata & 0,16 & 0,20 & 1,25 & 0,13 & 0,10 & 0,77 \\
\hline Caconde & 0,64 & 0,26 & 0,41 & 1,08 & 0,54 & 0,50 \\
\hline Divinolândia & 0,14 & 0,26 & 1,86 & 0,15 & 0,08 & 0,53 \\
\hline Esp. St ${ }^{\circ}$ Pinhal & 0,30 & 0,52 & 1,73 & 0,30 & 0,21 & 0,70 \\
\hline Itobi & 1,20 & 3,48 & 2,90 & 1,29 & 3,07 & 2,38 \\
\hline Mococa & 0,20 & 0,12 & 0,60 & 0,35 & 0,11 & 0,31 \\
\hline $\mathrm{St}^{\circ}$ Ant $^{\circ}$ Jardim & 0,27 & 0,27 & 1,00 & 0,21 & 0,17 & 0,81 \\
\hline S. J. Boa Vista & 0,49 & 0,21 & 0,43 & 0,63 & 0,28 & 0,44 \\
\hline S. J. Rio Pardo & 0,16 & 0,10 & 0,63 & 0,38 & 0,24 & 0,63 \\
\hline S. Sebast. Grama & 0,17 & 0,17 & 1,00 & 0,45 & 0,30 & 0,67 \\
\hline Tapiratiba & 0,17 & 0,10 & 0,59 & 0,37 & 0,27 & 0,73 \\
\hline Vargem Grande do Sul & 0,52 & 0,34 & 0,65 & 0,73 & 0,43 & 0,59 \\
\hline
\end{tabular}

Fonte: SR 5 - SUCEN

*C.V. = Desvio Padrão

Média 
TABELA 3

Postos para média e coeficiente de variação (C.V.) dos índices de infestaçăo e a classificação por infestação de domiclio e peridomiclio dos munićpios da encosta ocidental da Mantiqueira Paulista, 1974 a 1983

\begin{tabular}{|c|c|c|c|c|c|c|c|c|}
\hline \multirow[b]{3}{*}{ Município } & \multicolumn{4}{|c|}{ Domiclio } & \multicolumn{4}{|c|}{ Peridomićlio } \\
\hline & \multicolumn{2}{|c|}{ Posto } & \multirow{2}{*}{ Soma } & \multirow{2}{*}{ Clas. } & \multicolumn{2}{|c|}{ Posto } & \multirow{2}{*}{ Soma } & \multirow{2}{*}{ Clas. } \\
\hline & Média & C.V. & & & Média & c.v. & & \\
\hline Águas da Prata & 10,5 & 9,0 & 19,5 & $11^{\circ}$ & 12,0 & 10,0 & 22,0 & $11^{2}$ \\
\hline Caconde & 2,0 & 1,0 & 3,0 & $1^{2}$ & 2,0 & 3,0 & 5,0 & $1^{\circ}$ \\
\hline Divinolândia & 12,0 & 11,0 & 23,0 & $12^{\circ}$ & 11,0 & 4,0 & 15,0 & $7^{8}$ \\
\hline Esp. St ${ }^{\bullet}$ Pinhal & 5,0 & 10,0 & 15,0 & $8^{9}$ & 9,0 & 8,0 & 17,0 & $9^{9}$ \\
\hline Itobi & 1,0 & 12,0 & 13,0 & $6^{9}$ & 1,0 & 12,0 & 13,0 & $6^{2}$ \\
\hline Mococa & 7,0 & 4,0 & 11,0 & $4^{9}$ & 8,0 & 1,0 & 9,0 & $4^{2}$ \\
\hline $\mathrm{St}^{8}$ Ant $^{8}$ Jardim & 6,0 & 7,5 & 13,5 & $7^{\circ}$ & 10,0 & 11,0 & 21,0 & $10^{\circ}$ \\
\hline S. J. Boa Vista & 4,0 & 2,0 & 6,0 & $2^{\circ}$ & 4,0 & 2,0 & 6,0 & $2^{2}$ \\
\hline S. J. Rio Pardo & 10,5 & 5,0 & 15,5 & 99 & 6,0 & 6,0 & 12,0 & $5^{2}$ \\
\hline S. Sebast. Grama & 8,5 & 7,5 & 16,0 & $10^{\circ}$ & 5,0 & 7,0 & 12,0 & $5^{\circ}$ \\
\hline Tapiratiba & 8,5 & 3,0 & 11,5 & $5^{2}$ & 7,0 & 9,0 & 16,0 & $8^{2}$ \\
\hline Vargem Grande do Sul & 3,0 & 6,0 & 9,0 & $3^{9}$ & 3,0 & 5,0 & 8,0 & $3^{9}$ \\
\hline
\end{tabular}

Fonte: SR 5 - SUCEN

\section{TABELA 4}

Indice de "notificação de barbeiros" por ano segundo municipios da encosta ocidental da Mantiqueira Paulista, 1974 a 1983

\begin{tabular}{|c|c|c|c|c|c|c|c|c|c|c|c|c|c|c|c|c|c|}
\hline \multirow[b]{2}{*}{ Municipio } & \multirow[b]{2}{*}{74} & \multirow[b]{2}{*}{75} & \multirow[b]{2}{*}{76} & \multirow[b]{2}{*}{77} & \multirow[b]{2}{*}{78} & \multirow[b]{2}{*}{79} & \multirow[b]{2}{*}{80} & \multirow[b]{2}{*}{81} & \multirow[b]{2}{*}{82} & \multirow[b]{2}{*}{83} & \multirow{2}{*}{$\begin{array}{l}\text { Mé- } \\
\text { dia }\end{array}$} & \multirow{2}{*}{\multicolumn{2}{|c|}{ dp. 6 C.V. }} & \multicolumn{4}{|c|}{ Postos } \\
\hline & & & & & & & & & & & & & & média & C.V & soma & clas. \\
\hline Águas da Prata & 0,11 & 0,09 & 一 & 0,09 & 0,37 & 0,18 & 一 & 0,26 & 0,17 & 0,32 & 0,16 & 0,13 & 0,81 & 8 & 2 & 10 & $3^{2}$ \\
\hline Caconde & 0,32 & 0,33 & 0,04 & 0,16 & 0,32 & 0,29 & 0,39 & 0,22 & 2,92 & 1,31 & 0,63 & 0,88 & 1,40 & 2 & 8 & 10 & $3^{9}$ \\
\hline Divinolândia & 0,43 & 一 & 一 & 一 & 0,12 & 0,05 & 一 & 0,15 & 0,56 & 0,10 & 0,14 & 0,12 & 1,36 & 9 & 7 & 16 & $7^{8}$ \\
\hline Esp. St ${ }^{\circ}$ Pinhal & 0,11 & 一 & 0,14 & 0,07 & 0,11 & 0,12 & 0,11 & 0,11 & 0,64 & 0,41 & 0,18 & 0,19 & 1,06 & 6 & 5 & 11 & $4^{\circ}$ \\
\hline Itobi & 0,20 & 0,12 & 一 & 一 & 0,21 & 一 & 0,12 & 0,47 & 0,68 & 0,71 & 0,25 & 0,27 & 1,06 & 5 & 6 & 11 & $4^{2}$ \\
\hline Mococa & 0,10 & - & 一 & 0,08 & 0,06 & 0,13 & 0,05 & 0,03 & 0,48 & 一 & 0,09 & 0,14 & 1,56 & 11 & 12 & 23 & $8^{8}$ \\
\hline St $^{2}$ Ant ${ }^{2}$ Jardim & 0,29 & - & 一 & - & - & 0,28 & 0,19 & 一 & 0,27 & 0,22 & 0,13 & 0,13 & 1,00 & 10 & 4 & 14 & $6^{\circ}$ \\
\hline S. J. da Boa Vista & 1,04 & 0,40 & 0,16 & 0,61 & 0,63 & 0,70 & 0,24 & 0,36 & 1,67 & 1,28 & 0,71 & 0,48 & 0,68 & 1 & 1 & 2 & $1^{2}$ \\
\hline S. J. do Rio Pardo & 0,72 & 0,38 & 0,08 & 0,11 & 0,05 & 0,29 & 0,14 & 0,06 & 0,70 & 0,32 & 0,29 & 0,25 & 0,86 & 4 & 3 & 7 & $2^{2}$ \\
\hline S. Sebast. Grama & 0,06 & 一 & 0,05 & 0,15 & 0,15 & - & 0,21 & 0,16 & 1,24 & 1,08 & 0,31 & 0,46 & 1,48 & 3 & 10 & 13 & $5^{\circ}$ \\
\hline Tapiratiba & 一 & - & 一 & 0,14 & 0,07 & 一 & 0,13 & 一 & 0,38 & 0,07 & 0,08 & 0,12 & 1,50 & 12 & 11 & 23 & $6^{\circ}$ \\
\hline Vargem Grande do Sul & 0,23 & - & - & 0,07 & - & 0,07 & 0,13 & 一 & 0,65 & 0,59 & 0,17 & 0,25 & 1,47 & 7 & 9 & 16 & $7^{8}$ \\
\hline
\end{tabular}


de tempo entre a notificação e o seu atendimento.

$\mathrm{Na}$ Tabela 2 temos registradas as médias dos índices de infestação para cada município, acompanhadas dos correspondentes desvios padrão e coeficientes de variação.

A Tabela 3 apresenta a classificação dos municípios de acordo com o índice de infestação, que foi obtida pela soma dos postos alocados à média $e$ aos coeficientes de variação.

Na Tabela 4 são mostrados os valores dos índices de notificação por município, suas respectivas médias, desvios padrão e coeficientes de variação. Além đisso, também constam os postos alocados para as médias e coeficientes de variação, sua soma e finalmente a classificação dos municípios de acordo com o índice de notificação.

Comparando essas duas classificações (Tabela 5),observa-se que não há uma correspondência clara entre infestação e notificação. A pesar dos erros possíveis gerados por este método, acredita-se que os resultados obtidos no que diz respeito à relação entre índice de infestação e índice de notificação, não devam ser desprezados. Favorecendo ainda este ponto, tem-se que ao se analisar esta relação em um mesmo município, com os valores anuais destes índices, obteve-se resultados semelhantes. Observando-se a Figura 3 que mostra gráficos dos municípios de Caconde, São João da Boa Vista, Vargem Grande do Sul e São José do Rio Pardo, não se percebe correspondência entre os anos de maior infestação com os anos de maior notificação. Não se encontrando também correspondência com os anos anteriores ou subseqüentes. Esta figura apresenta apenas os índices de infestação no domicílio, porém os gráficos em que se utilizaram os índices de infestação no peridomicilio apresentaram resultado semelhante.

De posse dos dados obtidos observou-se que os municípios que apresentaram maior número de notificações no período estudado foram justamente os que sediam as equipes de campo da SUCEN, na área: Caconde, São João da Boa Vista e São José do Rio Pardo. De acordo com a classificação dos municípios da área por índices de notificação, eles se situam nos 3 primeiros lugares. No entanto, na classificação dos municípios por índice de infestação, apesar de Caconde e São João da Boa Vista continuarem nos primeiros lugares, São José do Rio Pardo vai para o nono lugar. Em contrapartida, 0 município de Vargem Grande do Sul que é o terceiro na classificação por índice de infestação, está em penúltimo lugar na classificação por índice de notificação. Levantou-se, então, a questão de que o índice de notificação poderia estar mais relacionado com a infestação em casas habitadas do que com a infestação no total de casas pesquisadas. Vale ressaltar que na área composta pelos 12 municípios estudados existe uma proporção elevada de casas desabitadas e abandonadas na zona rural (Forattini e col. 3, 1977). Observou-se, no entanto, que o município de São José do Rio Pardo apresentou nos anos de 1981 e 1983, na atividade de rotina, uma percentagem média de infestação em casas habitadas de

TABELA 5

Classificação segundo índice de infestação e índice de notificação de barbeiro dos municípios da encosta ocidental da Mantiqueira Paulista, 1974 a 1983

\begin{tabular}{|c|c|c|}
\hline Ordem & Indice de Infestação & Indice de Notificação \\
\hline $1^{2}$ & Caconde & São João da Boa Vista \\
\hline $2^{\circ}$ & São João da Boa Vista & São José do Rio Pardo \\
\hline $3^{9}$ & Vargem Grande do Sul & Caconde/Águas da Prata \\
\hline $4^{2}$ & Mococa & Esp. St ${ }^{2}$ Pinhal/Itobi \\
\hline $5^{\circ}$ & Tapiratiba & São Sebastião da Grama \\
\hline $6^{\circ}$ & Itobi & Santo Antonio do Jardim \\
\hline $7^{2}$ & Santo Antonio do Jardim & Divinolândia/Vargem G. Sul \\
\hline $8^{2}$ & Espírito St Pinhal & Mococa/Tapiratiba \\
\hline 92 & São José do Rio Pardo & \\
\hline $10^{\circ}$ & São Sebastião da Grama & \\
\hline $11^{2}$ & Águas da Prata & \\
\hline $12^{2}$ & Divinolândia & \\
\hline
\end{tabular}



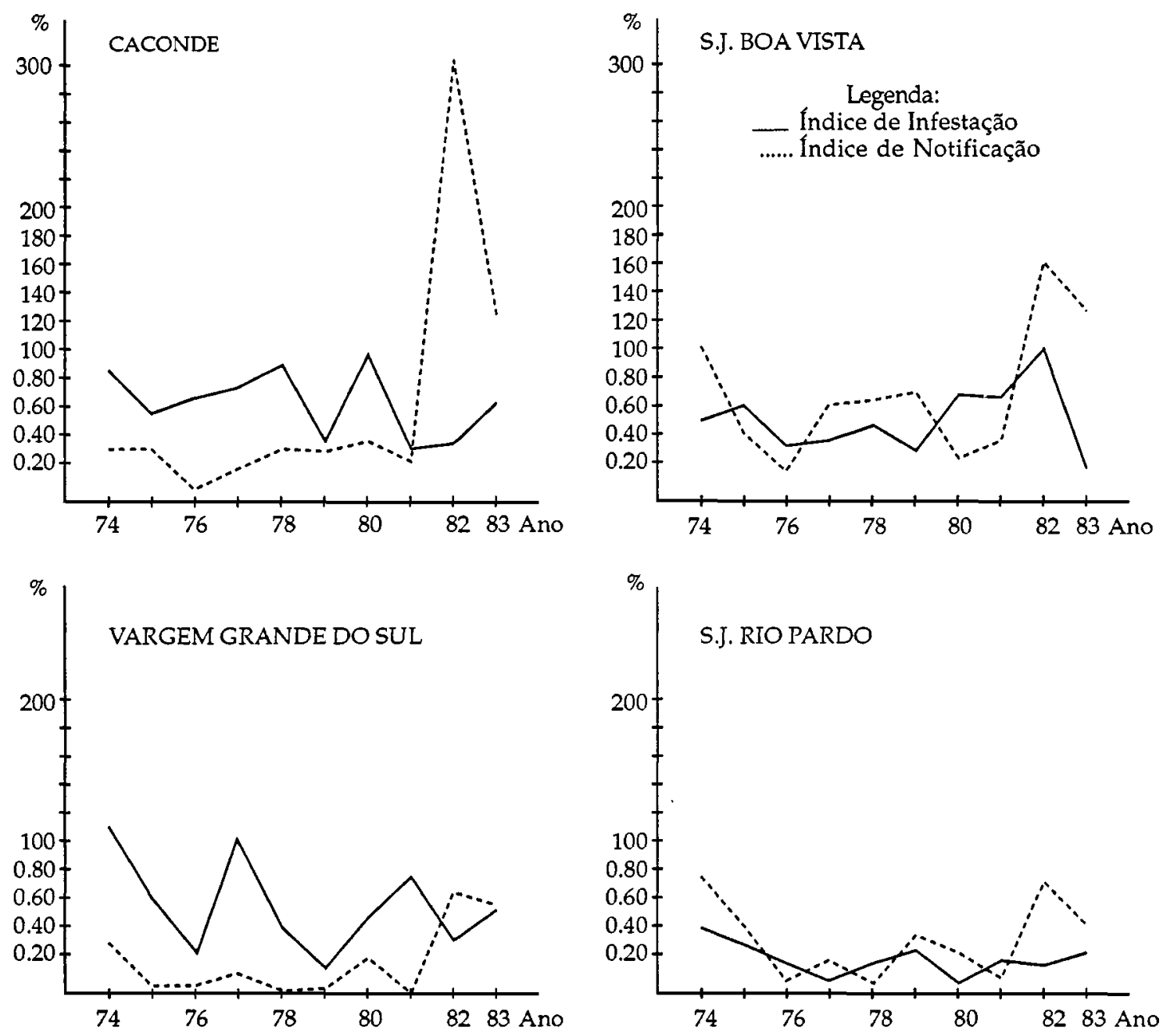

Fig. 3 - Indice de infestação e índice de notificaçāo de barbeiros, por ano, para os municípios de Caconde, São João da Boa Vista, São José do Rio Pardo e Vargem Grande do Sul. Fonte: SUCEN - SR.5 - Campinas.

$67,2 \%$ em relação à infestação em casas desabitadas. Nos mesmos anos, o Município de Vargem Grande do Sul apresentou uma percentagem média de infestação em casas habitadas de 72,2\% em relação às desabitadas. Além disto, os municípios de Caconde e São João da Boa Vista apresentaram para os mesmos anos uma percentagem média de infestação em casas habitadas de $66,1 \%$ e $49,8 \%$, em relação a de casas desabitadas. Esclarecidos estes pontos mantem-se a observação da ausência de relação evidente entre notificação e infestação seja nos municípios entre si, seja num mesmo município.

\section{DISCUSSÃO}

O fato de os municípios que apresentaram maior número de notificaçōes terem sido justa- mente os que sediavam as equipes da SUCEN na área, levou aos seguintes questionamentos:

1 - seriam estes os municípios com maior infestação na área?

2 - Ou estaria o maior número de notificações relacionado com o fato de os funcionários das equipes, ao terem sede no próprio município, executarem um trabalho educativo mais constante e atenderem mais prontamente às notificaçōes? (Não foi encontrado registro a respeito dos critérios de escolha dos municípios que iriam sediar as equipes por ocasião da estruturação do serviço de controle).

As classificações dos municípios por índice de notificação e de infestação mostraram que para os 
Municípios de Caconde e São João da Boa Vista, que sediam equipes, a relação entre maior infestação e maior notificação ocorreu. Já para o Município de São José do Rio Pardo, que sedia a outra equipe, esta relação não se evidenciou.

O esperado é que haja maior notificação em locais com maior infestação. A relação encontrada entre notificação e dispersão da espécie está de acordo com o esperado. No entanto, a observada ausência de relação evidente entre índices de infestação e de notificação levantou algumas hipóteses que apontam a necessidade de estudo mais pormenorizado tais como:

- a população provavelmente descobre, com maior freqüência, as formas triatomínicas adultas, recém-chegadas ao domicílio e decorrentes da dispersão da espécie;

- quando há foco (Wanderley' $\left.{ }^{12}, 1987\right)$ instalado no domicílio ou peridomicílio, a população tem mais dificuldades de detectá-lo, não gerando noti- ficações e sendo descoberto na sua maioria, pelas equipes de campo.

\section{CONCLUSÕES}

1 - Encontrou-se um maior número de notificações no último trimestre do ano quando comparados aos outros períodos, provavelmente é decorrência da dispersão ativa da espécie

2 - Pelo grande aumento no número de notificações observado a partir do ano de 1982 e pelo fato de os três municípios - que sediam as equipes de campo na área serem os que mais notificaram, concluiu-se que a população da área estudada respondeu à solicitação de colaboração no Programa de Controle da SUCEN.

3 - Não se evidenciou relação clara entre índice de infestação e índice de notificação, o que leva a se ter muita cautela ao inferir maior infestação em função do aumento no número de notificações ou vice-versa.

LIMA, V. L. C. de et al. [Aspects of "bug reporting" by the local population relating to Panstrongylys megistus surveillance in 12 counties of northeastern S. Paulo State, Brazil, 1974 to 1983]. Rev. Saúde públ., S. Paulo, 24: 497-505, 1990.

ABSTRACT: The importance of "bug reporting", on the part of the local human population, to the epidemiological surveillance of Chagas' disease in S. Paulo State is demonstrated. The variations the number of "bug reports" from the local human population in the period from 1974 to 1983 relating to an area, infested by Panstrongylus megistus, in the northeast of S. Paulo State are studied. An increase in the number of "bug reporting" occurring in October, November and December was observed; however, no connection was discovered between domiciliary infestation rate and the "bug report" rate in this specific area.

KEYWORDS: Trypanosomiasis South American, prevention and control. Panstrongylus. Insect control, standards. Consumer participation.

\section{REFERÊNCLAS BIBLIOGRÁFICAS}

1. BURALLI, G. M. Evolução do controle dos triatomíneos - domiciliados no Estado de São Paulo, São Paulo. 1986. [Dissertação de Mestrado - Faculdade de Saúde Pública da USP]

2. FORATTINI, O. P. et al. Aspectos ecológicos da tripanossomíase americana. VIII - Domiciliação de Panstrongylus megistus e sua presença extradomiciliar. Reo. Saúde públ., S. Paulo, 11: 73-86, 1977.

3. FORATTINI, O. P. et al. Aspectos ecológicos da tripanossomíase americana. XI - Domiciliação de Panstrongylus megistus e potencial enzoótico. Reo. Saúde pribl., S. Paulo, 11: 527-50, 1977.

4. FORATTINI, O. P. et al. Aspectos ecológicos da tripanossomíase americana. XIII - Potencial enzoótico doméstico em área de ocorrência de Panstrongylus megistus, sob vigilância epidemiológica. Rev. Saúde públ., S. Paulo, 12: $417-24,1978$.

5. FORATTINI, O. P. et al. Aspectos ecológicos da tripanossomíase americana. XVI - Dispersão e ciclos anuais de colônias de Triatoma sordida e de Panstrongylus megistus espontaneamente desenvolvidas em ecótopos artificiais. Reo. Saúde públ., S. Paulo, 13: 299-313, 1979.

6. FORATTINI, O. P. et al. Aspectos ecológicos da tripanossomíase americana. $X X$ - Desenvolvimento e ciclos anuais de colônias de Panstrongylus megistus em ecótopos artificiais no ambiente peri e extra domiciliar. Reo. Saúde publ., S. Paulo, 18:30$40,1984$. 
7. LITVOC, J. Doença de Chagas e estrutura social: infertação domiciliar e infecção humana em área submetida a açōes de controle. São Paulo, 1985. [Tese Doutorado - Faculdade de Medicina da USP].

8. ROCHA E SILVA, E. O. et al. Importância dos animais sinantrópicos no controle da endemia chagásica. Reo. Saúde públ., S. Paulo, 9:371-81, 1975.

9. ROCHA E SILVA, E. O. et al. Investigação de foco, uma das atividades das campanhas de controle dos transmissores da tripanossomíase americana. Reo. Saúde pübl., S. Paulo, 12:425-31, 1978.

10. SHERLCK, I. A. \& PIESMAN, N. J. Controle da doença de Chagas pelo combate aos vetores, com
Bendiocarb feito pelos habitantes. Reo. Soc. bras. Med. trop., 17:65-72, 1984.

11. SILVA, L: J. Evolução da doença de Chagas no Estado de São Paulo. Ribeiräo Preto, 1981. [Tese Doutorado - Faculdade de Medicina de Ribeirão Preto da USP]

12. WANDERLEY, D. M. V. Análise da atual estratégia do programa de controle da doença de Chagas no Estado de São Paulo. São Paulo, 1987. [Dissertação de Mestrado - Faculdade de Saúde Pública da USP]

Recebido para publicação em 24/7/1989

Reapresentado em 21/5/90

Aprodado para publicação em 19/7/90 